\title{
...bajo el dintel del putiadero: Estado, prostitución y violencia en Colombia y Brasil*
}

\author{
José Miguel Nieto Olivar**
}

\section{Resumen}

El presente artículo reflexiona sobre la relación violencia/prostitución en una lectura transversal de los contextos brasileño y colombiano, a partir de investigaciones de carácter antropológico realizadas desde el año 2006. Considerando la dimensión y la complejidad de esta relación, propongo un recorte concreto, etnográficamente basado en dos campos con niveles de profundidad diferentes: la relación del Estado con la idea/cosa-prostitución. La hipótesis es que para el Estado - concretamente para estos dos Estados - parece resultar interesante producir un tipo de prostitución en estrecha relación, virtual o efectiva, con diversas formas de violencia, generándose así, una prostitución como espejo invertido de la "democracia" y de la "modernidad". Esta prostitución así producida, mantiene una estrecha vinculación con la gestión social de personas, de cuerpos, de relaciones de género, de experiencias de sexualidad, de nociones de familia, de formas de trabajo específicas. Tomo como puntos de vista la zona de tolerancia del municipio de Puerto Berrio, Colombia, en 2007, y las narrativas de prostitutas históricas y militantes de derechos en la ciudad de Porto Alegre, Brasil, entre 2006 y 2009. Adicionalmente, abro el plano para mirar el "campo político de la prostitución" en orden nacional y global. En un juego de idas y vueltas, intento evidenciar conexiones, transformaciones y diferencias, tomando en cuenta las políticas nacionales así como los territorios y formas diversas de prostitución.

Palabras clave: Violencia, Prostitución, Género, Colombia, Brasil, Política.

\footnotetext{
* Recebido para publicação em 11 de maio de 2012, aceito em 18 de dezembro de 2012.

*** Núcleo de Estudos de Gênero - Pagu. escreve.ze@gmail.com
}

cadernos pagu (41), julho-dezembro de 2013:339-369. 
...Under the Sign of the Whore: State, Prostitution and Violence in Colombia and Brazil

\begin{abstract}
This paper reflects on the relationship violence-prostitution in an oblique reading of the Brazilian and Colombian contexts, from anthropological studies realized in 2006. Considering the dimension and the complexity of such relationship, I intend a concrete approach ethnographically funded in two fields with different depth levels: the relationship of the state to the idea-thing prostitution. The hypothesis is that, for the state - for both these states - it seems interesting to produce a type of prostitution in close relation, either virtual or effective, to the different forms of violence, thus generating prostitution as an inverted looking glass of "democracy" and "modernity". So produced a prostitution is closely linked to the social management of people, bodies, gender relations, sexuality experiences, notions of family, specific forms of labor. I take as point of view the prostitution zone of Puerto Berrios, Colombia, in 2007, and the narratives of historic prostitutes and human rights militants in Porto Alegre, Brazil, in 2006 and 2009. Additionally, I open my view to look at the "political field of prostitution" in the national and global order. In the two way game I try to evidence connections, transformations and differences taking into account national policies as well as territories and distinct forms of prostitution.
\end{abstract}

Key Words: Prostitution, Violence, Colombia, Brazil, Politics. 
Words, words and more meaningless words

('prostitution is violence against women', 'prostitution attacks the dignity of women', 'rescued women and victims') are accompanied by practices that cause great insecurity among those who sell sex on their own decision. Some uncomfortable questions. Colectivo Hetaira (Organización española en defensa de los derechos de las trabajadoras del sexo).

À Gabriela Leite, cuja morte se enreda nos labirintos dessas guerras.

\section{Puerto Berrío, Colombia: zona, suplicio y "post-conflicto"}

...en ese momento pasó por la otra calle el mechudo aquel que camina con aires de administrador general de la zona de tolerancia del pueblo. Es septiembre de 2007, estamos en Puerto Berrío (Ant), en la región central de Colombia, ribera del Río Magdalena; un pueblo de aproximadamente 35.000 habitantes con una historia de presencia militar y paramilitar muy importante (Olivar, 2008). Yenny, prostituta en el "Bar Piolín", me dice que él es "paraco"... o que por lo menos siempre se la pasa con ellos. ${ }^{1}$ Yo, el otro mechudo, al que ellas le insisten en que se corte el pelo, trabaja con una ONG respetada en la región.

Estamos sentados bajo el dintel de la cantina de Piolín, un hombre de la localidad que nació y creció entre putas, que administra el bar de su madre y ama jugar ajedrez. Esta es probablemente la cantina más pobre de la zona; una casita de inicio de siglo, sostenida apenas por la buena voluntad de Dios, bendita en goteras y con problemas en la red eléctrica. Piolín no es paramilitar ni tiene vínculos cercanos con ellos. Yenny tiene 30 años, es casi enana, también de la localidad. Como casi todas las que allí trabajan, vive en una pensión de la misma calle que, sin

1 "Paraco": forma coloquial para indicar que pertenece o hace parte de los grupos paramilitares. 
acueducto ni pavimentación, sin registros legales plenos, llaman "la cueva". Vemos a Patricia salir del burdel en el que trabaja. Localizado a pocos metros, en la esquina con la calle principal de la zona, es semejante a un club o discoteca de la capital, con mejor infraestructura que el bar de Piolín; las mujeres que allí trabajan suelen ser forasteras, más jóvenes, rotar con frecuencia. Su gerente es Juan... o Diego, o Efraín; un hombre de 30 años que, según algunos, es forastero y está vinculado con los paramilitares.

Al mechudo lo volví a ver unos días después en el parque principal. La noche del homenaje a la memoria de las víctimas locales asesinadas o desaparecidas en el marco del conflicto armado, que formó parte del llamado proceso de "Justicia y Paz" (4 de octubre de 2007). Lo vi llegar, lo vi circular por las fotos colgadas en los árboles, mirándolas casi todas, con detenimiento, comentando con sus amigos sobre muchas de ellas, algunas veces sin ninguna emoción... otras, con risas y gestos de desprecio. ¿Cuántas de estas personas habrán muerto por "putas" o por "maricas"? Encontré allí también a Patricia y a La Gordita paisa, prostitutas. Miraban las fotos, descansaban. Me dicen que el martes se van las dos para el Tolima (región más al sur, de la que es natural Patricia), que aquí la cosa está muy pesada, que allá ya tienen todo cuadrado, a dónde llegar, quién las va a recibir. Pesado quiere decir peligroso o económicamente desfavorable.

- Oiga, pero ¿todos estos muertos son de cuándo? Pregunta La Gordita de Medellín.

- Desde los años 80, yo creo - le respondo...

- Hmmmm - dicen en unísono - pero eso no es pues ni... ni la mitad. El poco 'e gente que matan aquí, ¿̇í o no?

- ¿Y ustedes no tienen muertos aquí? Pregunto.

- No... - dice Patricia - ...o no que yo sepa... también es bueno ver eso porque uno nunca sabe, ¿no? Yo tengo un hermano que hace como 3 años se despareció y nunca supimos nada de él... entonces quien sabe, en una de esas usted va y lo encuentra por ahí en una foto... 
- En Medellín - dice La Gordita -, hacen esto mismo, en toda una avenida, pero en la parte de abajo del ladrillo le escriben quien fue que lo jodió... si los paracos, si la guerrilla... en fin...

- Uhhhhh mucho más pesado, ¿no?

- Para mí es mejor así - explica Patricia -, la cosa no está pa' estar diciendo ese tipo de cosas... yo veo esos que se paran allá y hablan... imuy valientes! Aquí la cosa no está pa' eso... A mí me da mucho miedo... Vea que una vez yo vi asesinar a una compañera... Estábamos en Puerto Boyacá (municipio del departamento de Boyacá, también ribera del Río Magdalena, cercano de Puerto Berrío y famoso por su condición de "capital antisubversiva de Colombia"), así sentadas como estamos nosotros, frente a la cantina, cuando de repente baja un muchacho en una moto, se le para al frente y la llama por el nombre... ella voltea y el hombre la rosea a plomo, a mi lado... Yo quedé inmovilizada, tuvo que salir el dueño a levantarme y entrarme, no me podía mover... ese día me fui de ese pueblo y no volví nunca más...

(...)

- ...pero ¿sabe qué? El pela'o que la mató viajó en el mismo bus que yo. Yo me senté al lado de un señor y cuando veo es que este pela'o se está subiendo... Y antes de sentarse se me queda mirando... fijo... se sonríe y se sienta... Todo el viaje, hasta que él se bajó, estuve tiesa, sudando... más asustada!!!!!!!!!!!

- ¿Y por qué la mató?- Pregunto.

- Porque ella lo había robado. En otro pueblo. Y el man le hizo la persecución hasta que dio con ella y vea... Es que en esto uno tiene que trabajar derechito, ¿̇í o qué? Usted nunca sabe a quién roba, quién es el man que está ahí con uno... nunca se sabe quién es el hijueputa.

Patricia sabe "pre-reflexivamente" que ante el robo, la posibilidad es la muerte. No hay justicia civil intermediando. Hay

${ }^{2}$ Muchacho, hombre joven. 
hijueputas robados que, según su juicio, cobrarán. ${ }^{3}$ Como Puerto Berrío, Puerto Boyacá es uno de los municipios de la región media del Río Magdalena en los que el discurso y la presencia paramilitar están relativamente consolidados desde mediados de los años 80, en mutante simbiosis con las dimensiones legales del Estado. No sabemos si el muchacho que mató a la mujer en la parte final de la escena es paramilitar o no, pero es necesario pensar que en un control tan presente como el narrado, y como el que yo mismo tuve que ver y negociar en campo, él haya actuado, por lo menos, bajo la omisión paramilitar... o de la fuerza pública legal. Sabemos sólo de su deslizar tranquilo, de la mujer masacrada y de la retirada de Patricia en pánico. ${ }^{4}$ Hoy me cuenta la historia, nuevamente con miedo, observando a los hombres que administran la zona mientras igual que el otro se deslizan entre muertos y desaparecidos. Es la celebración por la "transición política", en la que ella no parece creer. Que no se ve desde este murito en el que estamos sentados y desde el cual ella recuerda a su hermano.

En 2003 dio inicio un acuerdo entre el gobierno del Presidente Uribe y las Autodefensas Unidas de Colombia, tenía por objetivo la aparente desmovilización de esta organización paramilitar. En 2005 se aprueba, con la vehemencia del Congreso Nacional, la Ley 975 de 2005 o "Ley de Justicia y Paz", que le permitía al gobierno ofrecer a los paramilitares lo que habían deseado. ${ }^{5}$ Objeto de grandes dudas y críticas desde el inicio, el proceso continúa hasta 2006, presentado a través de los medios

3 Sobre violencia sexual ejercida contra mujeres en el contexto del conflicto armado, ver Oxfam (2010).

4 En otros lugares desarrollé ya una presentación más detallada de Puerto Berrío, así como algunos análisis sobre la relación entre la guerra en Colombia, la prostitución y las violencias vinculadas con género y sexualidad (Olivar, 2008; Olivar \& Pacheco, 2012).

5 Informe oficial del proceso de desmovilización: <http://www.reintegracion.gov.co/Es/proceso_ddr/Paginas/proceso_paz.aspx > .

Ley de Justicia y Paz: <http://www.cdh.uchile.cl/anuario04/6Perspectivas_regionales/Ley1_975.pdf $>$. Informe de la Comisión Interamericana de Derechos Hümanos de 2004: > . Ver también: Álvaro (2009). 
de comunicación como un modelo de paz. El espectáculo fue completo: entrega de armas, desmovilización de más de 30.000 combatientes, rendición de cuentas, confesión de crímenes, peticiones de perdón, reducción de penas, y otorgamiento de haciendas como cárceles para los comandantes, entre otras perlas. Todo a cambio de la verdad. Entre desmovilizaciones masivas, "Justicia y Paz", la difusión de una cierta sensación de seguridad, alguna reducción de la intensidad del conflicto armado, la multiplicación territorial de las bases militares, el aumento de la participación paramilitar en el poder político y el crecimiento de las concesiones mineras, comenzó entonces la idea de un "posconflicto". 6

Los "desmovilizados" conformaron un nuevo actor que comenzó a ocupar el cotidiano político y civil de la ciudad. Hermanos de alguien, enemigos de otros, ellos eran competidores diferenciados en mercados sexuales, matrimoniales, laborales. Los "desmovilizados", como personajes en este escenario, eran el interruptor entre la guerra y la "paz concedida"; al mismo tiempo invisibles y por todo mundo conocidos, eran la encarnación de la esperanza y del miedo, del rencor y del eufemismo en los comentarios de muchos habitantes de Puerto Berrío. Y las putas lo sabían. Pues en las "zonas de tolerancia", por un lado, el mundo de la política gira en tiempo diferente (entre regalías inmediatas a cambio de votos y cambios que demoran vidas), y por el otro, entre aguardientes y rancheras, entre clientes y rumores, las "zonas" tejen otro sistema de conexiones e informaciones. Ahí está Patricia en su prostíbulo de esquina, que se quiere ir de aquí, que entiende que es una valentía desproporcionada mostrar la cara y denunciar.

Corría la información en diversos círculos sociales de que los dos candidatos a la alcaldía más votados en 2007, fueron financiados por dos poderosos jefes paramilitares de la región:
${ }^{6}$ Ver,
por ejemplo,
el discurso
policial: $<$ http://oasportal.policia.gov.co/portal/page/portal/UNIDADES_POLICIALES/Dire cciones_tipo_Operativas/Direccion_de_Investigacion_Criminal/Documentacion/V olumen\%20N̄o.\%2051-1/Posconflicto\%20en\%20Cōombia.pdf > . 
Ernesto Báez y el Comandante Julián Bolívar, llamado "el Señor". El candidato electo, en el día de las elecciones, fue visto circulando en una moto con "Chayanne", joven jefe local paramilitar... muerto inmediatamente después de las elecciones. En el homicidio resultó herido "Ricardo", administrador de una famosa cantina en la zona de tolerancia, $y$, al parecer, colaborador de "Chayanne".

"Chayanne", y esta información proviene de jóvenes locales, era también conocido como "el muchacho de la Plaza", "el paraco del Mercado", visto un par de años antes por algunos habitantes del barrio popular "El Oasis" violando y torturando junto con otros, "por odiosa", a una muchacha de 17 años habitante del barrio. Su cuerpo, así como el de varias otras mujeres en aquel tiempo, amaneció en uno de los pozos de agua en la cima del cerro. "Odiosa", en el contexto, significa una sola cosa: que repudiaba los piropos y las peticiones sexuales de los muchachos. Contra-efectuación de la puta.

Entre 2000 y 2002 trabajé en una ONG en la región del Magdalena Medio. En ese tiempo, en municipios como Puerto Berrío, La Gloria, Barrancabermeja, Aguachica, Morales, Sabana de Torres, las narraciones respecto a amenazas, asesinatos crueles y torturas a personas por "odiosas", "putas" y "maricas", los desplazamientos individuales o familiares por diagnósticos públicos de $\mathrm{VIH}$, fueron recurrentes. ${ }^{7}$ Todos estos municipios estaban, o comenzaban a estar, bajo control paramilitar $y$ contaban con cuerpos de policía y con la presencia de unidades de las fuerzas militares legales.

La prostitución (trabajo sexual) no es el único espacio en el cual los actores armados ejercen un poder directo de control y cocreación de la sexualidad y del género en interrelación con otros

7 Sobre la relación entre violencia sexual, género y guerra en Colombia existe un esfuerzo importante de ONGs de derechos humanos por compilar información. El panorama es dramático. Ver, por ejemplo: Mujer y Conflicto armado, 2002; Amnistía Internacional, 2004; Barraza y Caicedo, 2007; Oxfam, 2010; Humanas, 2009 y 2011. Desde una perspectiva más académica, ver por ejemplo: Prada, 2012. 
marcadores de diferencia. De la misma forma, no es solamente en la "zona" donde la prostitución y otras formas de "sexo transaccional" o de participación en los mercados del sexo suceden. ${ }^{8}$ Sin embargo, prostitución (sexualidad, afectos, trabajo, corporalidades) y zona, operan como espacios imaginarios y materiales de articulación y gestación de formas específicas y parecidas de violencia. ${ }^{9}$ La zona de tolerancia, por ser un lugar en el que prácticamente la ciudad se suspende, ocupa un lugar especial en nuestro análisis.

En Colombia, como en Brasil, la prostitución practicada por un adulto no está prohibida por los Códigos Penales; sin embargo, cualquier actividad a su alrededor, comercial o no, que implique la "inducción", el "constreñimiento", la facilitación o el lucro, es considerada crimen. Eso correspondería a un modelo abolicionista. En el caso brasileño la "manutención de casas de prostitución" es crimen, pero en el colombiano no, pues está legislado en el marco del Código Nacional de Policía de 1970, de inspiración reglamentarista. En este código se prevé sin ninguna especificidad la reglamentación de la prostitución así como la especial disposición del estado para la "rehabilitación" de las prostitutas (artículos 178 a 183). Capilarmente, el código nacional se traduce en códigos departamentales y municipales, en los que la reglamentación se traduce en previsión de establecimiento legal de "zonas de tolerancia". ${ }^{10}$ La "zona" es un territorio delimitado

8 Un segmento importante de mercado era el de las "call-girls" (llamadas en Colombia como "prepagos"). Según un joven que trabajaba en los ramos del entretenimiento y del transporte, este negocio, en 2007, era coordinado por una mujer con influencias políticas, y su principal clientela eran "los señores" (Olivar, 2008).

9 Esto en el sentido en el que Das (2008) piensa género como conector de planos nacionales, domésticos y subjetivos. Así, prostitución y zona, operan como formas concretas (al mismo tiempo imágenes y materializaciones) de ese conector y son, a su vez, conectores de género.

${ }^{10}$ Ver los de Antioquia y Bogotá: <http://www.medellin.gov.co/irj/go/km/docs/wpccontent/Sites/Subportal\%20del\%20Ciu dadano/Medio\%20Ambiente/Secciones/Plantillas\%20Gen\%C3\%A9ricas/Documentos/2 
por decreto, descrito en los Planes de Ordenamiento Territorial de cada municipio, y procesualmente confinado. En ella, y sólo en ella, puede existir legalmente oferta de servicios sexuales, así como burdeles y demás formas de comercialización y lucro de terceros, siempre y cuando pasen por la revisión y aprobación de las autoridades locales de salud, policía y, en algunos rarísimos casos, bienestar social. No se prevé ningún tipo de control, regulación o protección laboral. ${ }^{11}$

La zona de tolerancia de Puerto Berrío está ubicada en el límite del centro de la ciudad, ayudando a definirlo; a pocas cuadras está el parque principal y los edificios de gobierno. Es un sector de intensa movilidad comercial y de flujo constante de carros y peatones durante el día. Por las noches, especialmente en fines de semana de pagos, es el escenario de una gran fiesta pública de jóvenes y adultos, rurales y urbanos, civiles y militares. En 2007, ni las secretarías de salud municipal y departamental, ni ninguna otra agencia del estado civil, ni ninguna ONG, tenían acciones en la zona. Algunos funcionarios habían manifestado el deseo de implantar un sistema de carnés sanitarios. La presencia de la policía se limitaba a rondas de dos o cuatro agentes en moto. El paisaje narrativo de esta zona era fuertemente marcado por esas violencias de las que Patricia nos hablaba, pero también por míticas batallas campales entre prostitutas y clientes, por violencias anteriores a la prostitución (familiar, conyugal, militar), por expresiones del estigma y la discriminación (prostíbulo quemado, madre que se avergüenza pero usufrue de la hija con culpa, dinero maldito, insultos al salir de la zona)... y por la sensación de fuerza y libertad, por la memoria de grandes amores, de disoluciones

011/Fauna\%20Tenencia/ORDENANZA_018_CODIGO_DE_CONVIVENCIA.pdf $>\quad y$ $<$ http://www.alcaldiabogota.gov.co/sisjur/normas/Norma1.jsp?i=6671>.

${ }^{11}$ En 2010 la Corte Constitucional de Colombia profirió una Sentencia (T6292010) en la que se reconoce la legitimidad jurídica del trabajo sexual y se le exige al gobierno de Bogotá, y por extenso a los ministerios nacionales, la definición de políticas públicas que protejan los derechos laborales de los y las trabajadoras del sexo. Sobre la Sentencia ver: Arango (2010) y Olivar (2010b). 
conyugales y de momentos de celebración de sus vidas. Por lo menos en dos ocasiones presencié peleas entre clientes, con botellas quebradas, que fueron disueltas por esos hombres como el mechudo. ${ }^{12}$

Según diversas personas, esta zona era controlada por paramilitares, explícitamente llamados así, y se constituía, en la visión de no-frecuentadores, como un territorio de peligro. La categoría "desmovilizados" era usada sólo como un eufemismo, y las mujeres solían amenazar a sus enemigos situacionales, en broma o seriamente, con un "le voy a mandar a los paracos".

Es necesario aclarar que ser controlada por paramilitares no es una característica particular de la zona de Puerto Berrío. Una trabajadora sexual caleña que conocí en Leticia, en el extremo sur del "trapecio amazónico", ciudad fronteriza con Brasil y Perú, me contaba en 2011 que parte de las razones para haber emigrado hacía allá, era el miedo que le producían algunos de los otros lugares en los que había trabajado. ${ }^{13}$ Me contó, por ejemplo, que en la zona de tolerancia de la ciudad de Acacías (Meta), "los paracos" ejercían amenazas constantes y control total, algunas de sus colegas fueron intimadas, asesinadas o desaparecidas. A Acacías había llegado proveniente de un periplo laboral que incluyó el norte del departamento del Valle, región cercana a la ciudad de Cali, donde vivía. Pero de allá salió porque "la cosa se puso muy caliente" hacia 2007, cuando las BACRIM ${ }^{14}$ tomaron control de la región y de las zonas de tolerancia.

12 Restrepo (2007) nos narra ricamente la historia de la zona de tolerancia de Barrancabermeja. Ávila (2012) evidencia la violencia latente en una de las zonas de tolerancia de Bogotá llamada, eficazmente, de "Cuadra Picha".

${ }^{13}$ Las otras razones eran, de un lado, la posibilidad de ganar más (mínimo 50.000 pesos por el "rato" / US\$ 30), y por el otro, porque el relativo aislamiento de Leticia garantiza un anonimato que muchas personas -no sólo prostitutas- buscan.

${ }^{14}$ Después de desmovilizados los paramilitares, fueron apareciendo paulatinamente las denominadas "Bandas Criminales (BACRIM)", operando en prácticamente los mismos territorios y expandiendo su acción. En una conversación vía chat con una amiga de Puerto Berrío, en abril de 2012, me contaba que dos BACRIMs asolan la ciudad desde hace dos años (2010): Los 


\section{Porto Alegre, Brasil... tudo em OFF e a modernização da violência.}

¿Sabes lo que ellos hacían conmigo? Me capturaban, me llevaban pa'l área, pa'la Central, pa' quedar registrada allá, porque como yo no les daba dinero... Yo decía que no tenía marido. Y le decía al Alemán [su marido], ni te aparezcas por allá, déjalo en mis manos. ¿Darles mi dinerito a ellos???? (...)

Quien nos habla es Janete, prostituta desde el final de la década de 70 en el centro de Porto Alegre, capital del estado de Rio Grande do Sul, y militante del movimiento gaucho y brasilero de prostitutas. Nos habla de un mundo que, con ella y sus colegas, podemos situar en la región central de esta ciudad entre el año 1980 y, más o menos, el año 1993. El pacto que nos describe la hizo ganarse el sobrenombre de "cuerpo sin futuro", entre los policías de la época. Era ese el apodo, según cuenta, que recibían de ellos las mujeres que encarnaban la prostitución callejera sin un marido que las protegiera. Ella y muchas de las mujeres de aquella generación (nacidas alrededor del año 60) que trabajaron en la prostitución callejera en el centro de Porto Alegre, sufrieron los abusos sistemáticos de las policías de la época. Padecieron la existencia de las Delegacias de Costumes ${ }^{15}$, de los "PP" (Pago a la Policía) y de la perversa alianza entre sus maridos/chulos y la policía. A algunas no les gusta hablar de esta violencia, algunas la narran apenas para hablarnos de su propia fuerza y agresividad; sin embargo, para algunas, como Soila, esa violencia ocupaba, entre 2006 y 2008, un lugar privilegiado en la memoria y en la

Rastrojos y Los Urabeños. Me habla ella de dos o tres muertes diarias. Inclusive su hermano está preso por participar de una de las bandas.

${ }^{15}$ Unidades de la policía civil que, como lo describe Rodrigues (2003), tuvieron el principal objetivo práctico de reprimir y controlar la prostitución. Su vehículo legal era el "Termo de Vadiagem". Vadiar significa vagabundear, perder el tiempo, estar sin trabajar. 
imaginación sobre sí (mujer, prostituta, militante, amante, esposa, ciudadana, trabajadora).

Cuando comenzó en la prostitución Soila tenía 15 o 16 años, y lo hizo, como era frecuente en la época, en un juego entre deseo $y$ chantaje que era fundamental en la configuración de sus relaciones conyugales. El Mimoso era un hombre con el doble de su edad y con bastante experiencia en asuntos como el del proxenetismo. A veces, mientras me narraba las historias, Soila se llamaba "víctima": no de la prostitución, sino de un orden de violencia masculina irreductible que tuvo un espacio privilegiado en su relación conyugal/familiar.

Mi primera vez en cana fue bien en el inicio, cuando trabajaba en la Volunta [Avenida Voluntários da Pátria, en el centro de la ciudad, un emblemático punto de prostitución de los años 80 y 90]. Los chulos pararon de darle dinero al Buda, él mandó capturar a todas las mujeres... En una de esas me cogieron y pasé 3 días en cana, allá en el Presidio Central. Había una "rata" ${ }^{16}$ que se llamaba Jackson, que era casado con una sobrina de Mimoso. Y ellos se odiaban (...)

Nos dieron choques eléctricos en la vagina, en los pezones, chorros de agua helada... (...) Lo que sé es que al final de esos dos días me montó en uno de esos Volkswagen blanco y negros de las "ratas" y comenzó a rodar conmigo por la ciudad... Y yo así... Atrás, en el piso del carro. Hubo un momento en que paró. El semáforo de la [calle] Garibaldi con la [Avenida] Farrapos... y el Michola [hermano de Mimoso] vino a hablar con él... Y yo no lograba decir nada:

- Bueno, hermano, diga cuánto es o qué, que el hombre dijo que le va a dar el billete que pida.

- Es tanto... - Un montón de dinero, pero no me acuerdo.

Entonces ellos hicieron los ajustes y me dejó alláááááááaaaaa en la Protásio [Avenida Protásio Alvez,

${ }^{16}$ En portugués "rato", nombre dado en aquellos tiempos y en aquellas calles a los miembros de la Policía Civil. 
zona norte de la ciudad]... así como yo estaba, cinco días en cana, con un vestidito azul. Me dejó ahí. Me quedé sentada. Fue pasando el tiempo, fue pasando el tiempo, hasta que Mimoso llegó.

Entré en el carro y bueno, ahí él se puso a torturarme para ver si Jackson me había comido o no...

Las historias narrables son muchas y ricas en detalles; sin embargo, hay una escena marcada de manera especial en la memoria de Soila, del Núcleo de Estudos da Prostituição (NEP, nombre de la asociación local de prostitutas) y de la Red Brasileña de Prostitutas. Es marzo del año 1989, en la esquina de las calles Dr. Flores y General Vitorino vemos un grupo de mujeres radiantes ofreciendo sus servicios sexuales. De repente llega una patrulla de la Policía Militar escoltando el microbús que siempre se las lleva. Algunas intentan correr, otras se esconden en bares, en garajes, y debajo de los carros. No hay negociación previa o posterior con los chulos. Simplemente se llevan a las mujeres. Ya dentro del microbús, y después de haber dado muchas vueltas por la ciudad, Soila entiende que está a camino de la Ilha das Flores. ${ }^{17}$ Es la segunda vez, y de esta, piensa, no va a salir viva. Entonces el vehículo se detiene, en un lugar que nadie identifica. Es un matorral. La puerta se abre y ellas reciben el primer chorro de gas lacrimógeno directamente en los ojos. En la Ilha algunas mujeres fueron amarradas a los troncos de los árboles, con la vagina expuesta a hormigas, insectos e infiernos. Fueron "comidas de cualquier manera" por todos los hombres uniformados que allí estaban. "Nos metían los dedos hasta donde querían y hasta donde no querían..." Sus ropas fueron rasgadas y la piel marcada con palmeta, recuerda ella. En la despedida, ellos les esparcieron más gas y les dijeron que se fueran por el medio de los matorrales. Al día siguiente, "batalhar". Con el desespero de la situación, con el miedo de que sucediera de nuevo, y con el

${ }^{17}$ La memoria colectiva recuerda la Ilha das Flores. La nota periodística habla de la Ilha da Pintada. 
estímulo de Tina y de Lúcia ${ }^{18}$, fue hecha una denuncia legal y llamada a una rueda de prensa.

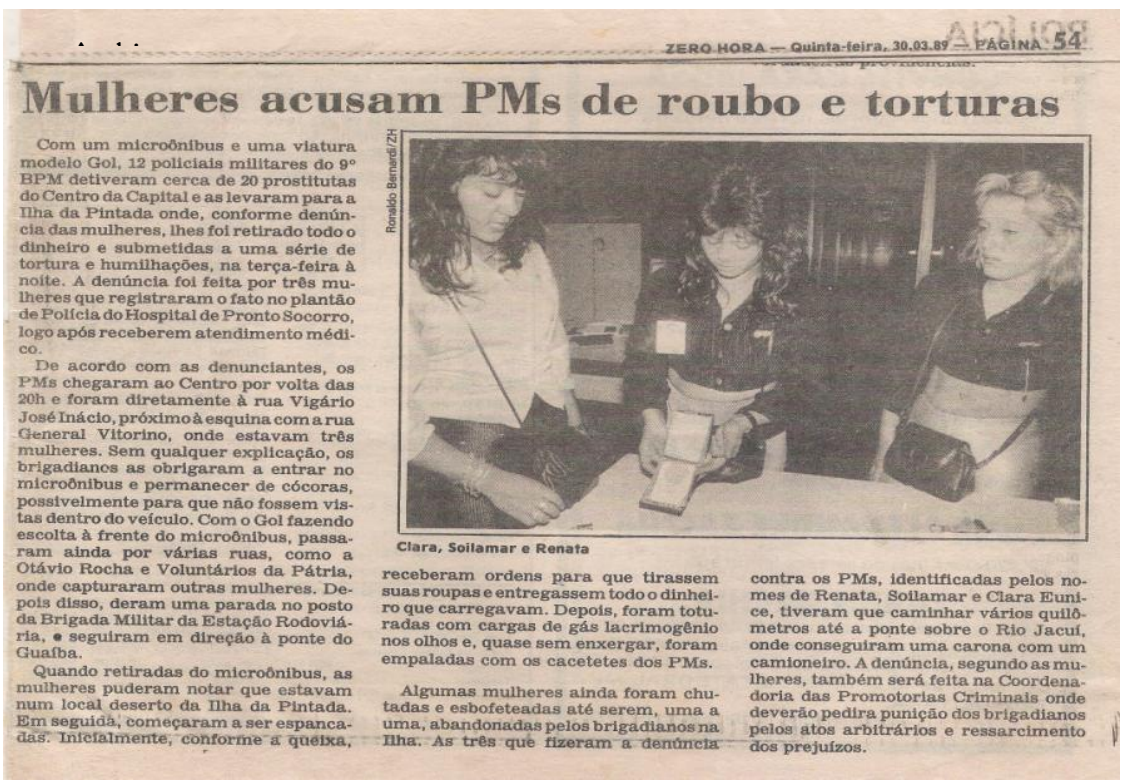

Recordemos que en el año 1986 tiene fin la dictadura militar en el Brasil y comienza la "transición a la democracia". Es decir, gran parte de la violencia aquí narrada sucede como parte de tal transición o, de hecho, ya en un periodo democrático. Es más, cuando les preguntaba a estas mujeres si esa violencia era debida a la dictadura, ellas decían que no.

**

18 Tina - mujer no-prostituta y defensora de derechos humanos - y Lúcia prostituta portoalegrense de la misma generación y lugar de trabajo que Soila -, fueron las fundadoras de la asociación de prostitutas de Porto Alegre, NEP (Núcleo de Estudos da Prostituição), en 1989. 
Durante los años 1990 la prostitución callejera en el centro de Porto Alegre, que se recuerda como masiva, festiva, expuesta, decididamente pública y provocativa, incómoda, fue prácticamente barrida. Con el paso de los años y de la democracia la prostitución se fue relegando a espacios privados. Sin embargo, la calle Garibaldi, que conecta en una cuadra a la Voluntários y a la Farrapos, en pleno centro de la ciudad, se mantuvo durante mucho tiempo como un reducto de prostitución callejera, decididamente pública. ${ }^{19}$ Pues bien, en 2007 acompañamos un operativo de la Policía Militar en esta cuadra destinado a, según información del periódico Correio do Povo de 8 de mayo de 2007, combatir la "prostituição infantil", el tráfico de drogas y la piratería (Olivar, 2010a). La policía de choque llegó en las horas de la noche junto con periodistas y fotógrafos, retuvo a las mujeres que se encontraban en la calle, ocupó los hoteles penetrando en los cuartos y ordenando que todo el mundo saliera. En denuncias públicas las mujeres declararon que algunas de ellas, como algún cliente, tuvieron que salir desnudas a la calle. Durante casi dos semanas policías hicieron plantón en esta cuadra impidiendo que las mujeres ocuparan la calzada. Fueron obligadas a mantenerse atrás de la puerta de hoteles y pensiones.

Algunos días después ellas activaron la asociación de prostitutas (NEP), su mecanismo de simetrización, que dio inicio a una serie de demandas y negociaciones con las instituciones implicadas y con organismos de protección de los Derechos Humanos. Se estableció que había sido orden directa del Secretario de Segurança Pública. En conversaciones del NEP con los policías de plantón se supo que la orden dada era "sacar a las

${ }^{19}$ Las calles Voluntários da Pátria y Avenida Farrapos, así como la Garibaldi y otras tantas calles y plazas en el centro de esta ciudad, son territorios históricos de prostitución. Hoy en la Voluntarios, por ejemplo, no es común encontrar prostitutas en la calle. En la Farrapos se encuentran mucho menos que antes, dicen varias personas; sin embargo, en la Farrapos hay aún algunos puntos, siempre en conflicto con las asociaciones de vecinos, y sobre todo, una amplia gama de clubes nocturnos vinculados al comercio sexual. 
mujeres de la calle". Uno de los policías, seducido intensamente por las mujeres, declaró que ellos sabían que era inconstitucional lo que hacían, que no entendía por qué los habían sacado de lugares donde los necesitaban más y, jugando con el límite entre el secreto, el chisme y el chiste, que todo debía haber sido porque la mujer del Secretario pasaba por esa calle en el carro y se sentía escandalizada. ${ }^{20}$

Como parte de las gestiones del NEP se realizó una audiencia en el Ministerio Público Estadual, a la que fue convocado el comandante del Batallón de la Policía Militar encargado del operativo. Se esperaba que allí el MPE ordenara el fin de la acción y la máxima protección a los derechos de las mujeres, pues estaban siendo flagrantemente violados. Esperanzas vanas. La discusión se perdió en no dichos y en discusiones sobre el tamaño de las faldas que las mujeres usaban en la calle, y terminó en un compromiso del NEP para hacer talleres de ciudadanía con las mujeres y de la Policía Militar para respetar sus derechos. Se buscó producir algo así como "putas decentes", putas que no recordaran ninguna imagen evidente de putas. Pero no se ordenó la suspensión de las acciones. "En off", como él mismo dijo, el Comandante del Batallón nos sugirió, a la salida de la reunión, que movilizáramos los medios de comunicación porque eso era un asunto político del Secretario. Volvió al secreto/chisme/chiste de la esposa evangélica o de la visita Papal al Brasil, todos reímos y nada pasó.

Esa historia no es excepcional. Con alguna frecuencia llegan al NEP mujeres quejándose de violencia y discriminación. Una de ellas, cierta vez, contaba que había sido agredida por la policía en una plaza pública. Asustadas, las mujeres de la organización quisieron saber cómo: con una botella de plástico descartable. Sin

${ }^{20}$ En medio de sentidos comunes compartidos y seducciones mutuas, las prostitutas y los policías de plantón hicieron un acuerdo: las mujeres permanecían en la calle sin hacer mucho desorden y uno de los policías vigilaba la esquina por la que debería parecer la patrulla. Cuando él diera la señal, ellas se refugiaban en los hoteles. 
marcas, sin sangre; torpezas descartables, también. El símbolo se mantiene poderoso y, en condiciones de normalidad, no necesita más materialidad que la del propio gesto dramatúrgico para sustentarse, conectarse y re-producir su historia particular.

\section{Ampliando el cuadro.}

Cartagena, Colombia. Los días 14 y 15 de abril de 2012 se realizó en esta ciudad la Cumbre de las Américas. El evento estuvo precedido por un escándalo de prostitución hiper-publicitado que involucró agentes del cuerpo secreto de seguridad del Presidente Obama $^{21} y$ "escorts" colombianas en dicha ciudad.

Unos días después, Noticias Uno, un noticiero colombiano reconocido por su seriedad investigativa, realizó la siguiente denuncia. La policía de Cartagena, junto con miembros de una agencia de inteligencia colombiana, estaría buscando, lista en mano, en diferentes bares, a las mujeres implicadas. Solicitaban documentos y cuando las encontraban las retiraban del lugar. Las mujeres ya tendrían un abogado, quien denunció también que ellas se sentían amenazadas pues habían comenzado a percibir la presencia repetida de "gringos" con actitud vigilante y audífono en el oído. ${ }^{22}$ Unos días después se supo que la mujer protagonista había dejado el país y se encontraba en "algún lugar del mundo", escondida, que salió "prácticamente huyendo" y con miedo por represalias contra ella, su hijo o su familia. ${ }^{23}$

${ }^{21}$ Ver New York Times. <http://www.nytimes.com/2012/04/19/world/americas/colombian-escort-speaksabout-secret-service-scandal.html?pagewanted $=2 \& \_r=4 \&$ ref $=$ world $>$. Accesado en 27 de abril de 2012 .

$22<$ http://www.youtube.com/watch?v=_Q5hMcZ3z3k>. Accesado en 27 de abril de 2012.

${ }^{23}$ Audio de la entrevista disponible en: $<$ http://www.elespectador.com/noticias/nacional/audio-343677-entrevista-daniaconcedio-w-parte-i $>$. 
Hay un elemento que resalta el dramatismo y que nos conecta con el inicio de este artículo. "Lista en mano" es uno de los grandes símbolos de la violencia paramilitar en Colombia, una marca de su modus operandi aquí adoptada por la policía. Una herida en la memoria colombiana. "Lista en mano" está siempre presente en las narrativas de familias de desaparecidos o de sobrevivientes de masacres. El escándalo sirvió para ver la actuación para-legal de la Policía colombiana (y la incorporación estatal de prácticas criminales de terror), como en la historia de la calle Garibaldi en Porto Alegre.

Así, el "caso Cartagena" permite ver cómo se produce socialmente la idea-prostitución. Además de las amenazas y coerciones directas, fue una oportunidad aprovechada por algunos discursos de corte disciplinador o abolicionista. Si en la historia de la Garibaldi el asunto de las ropas de las mujeres ocupó gran parte del espacio retórico, y la "prostitución infantil" se usó como disculpa para reprimir policialmente ( $\mathrm{y}$ producir mediáticamente) el trabajo sexual, en el caso cartagenero fue, por supuesto: trata y explotación. ${ }^{24} \mathrm{El}$ escándalo cartagenero le sirvió a estos discursos, descritos por organizaciones de (y de apoyo a) prostitutas como violentos, para ganar espacio mediático y favorecer la producción de la necesidad de intervenciones de "mo(ral)dernización" (García, 2002). ${ }^{25}$

\footnotetext{
${ }^{24}$ En 2009 los códigos penales brasileño y colombiano introdujeron la categoría "explotación sexual" como substituto de prostitución. "Tráfico, trata y turismo sexual" constituyen junto con "explotación sexual" el agente político más fuerte contra la prostitución hoy en el mundo (Kempadoo, 1995; Agustín, 2007; Piscitelli, 2008, 2011b e 2011c). Son ideas que, en su base, se posicionan contra la prostitución. Ver, por ejemplo, las recomendaciones de 2012, de la CEDAW, para Brasil sobre violencia contra las mujeres (CEDAW, 2012), y las ideas de "modern slavery" y "modern abolicionism" promovidas por el Departamento de Estado de EUA en su reporte anual sobre Tráfico de Personas (http://www.state.gov/j/tip/rls/fs/2011/167226.htm).

${ }^{25}$ Es significativa la diferencia de contenido, tono y sentido de tres declaraciones públicas alrededor de este evento. Primero, la firmada por una organización de mujeres norteamericana y por el "Centro de pensamiento sobre trata" -
} 
La decimosegunda edición de la revista Research for Sex Work (2010), editada por la NSWP (Network for Sex Work Projects -red global de trabajadoras sexuales), trata exclusivamente sobre la relación prostitución y violencia. ${ }^{26} \mathrm{El}$ artículo "Their words are killing us", escrito por investigadoras que desde los años 90 apoyan a las organizaciones de trabajadoras sexuales de Australia y Nueva Zelandia, afirma que el lenguaje usado por las organizaciones abolicionistas es violento e irrespetuoso, y que puede favorecer el auto-estigma, la discriminación, el desprestigio de las organizaciones de prostitutas y la consecuente pérdida de recursos (como de hecho parece haber sucedido en Brasil), y la violencia física. "...their descriptions of sex workers' vaginas are more women-hating than those in any mainstream pornography" (Bannachie \& Marie, 2010:24).

Y las palabras se transforman en armas contra las cuales luchar; esto es, en tiempo y energía. De hecho, acompañando las discusiones de la Red Brasileña de Prostitutas a partir de 2009, se percibe que al conjunto de principales fuentes de vulneración $(\mathrm{VIH}$ y violencia física) se unieron con fuerza los discursos abolicionistas difundidos junto con la anti-trata y la anti-explotación sexual. Es decir, buena parte de la energía de militantes como Gabriela Leite se ha tenido que destinar a develar y contrarrestar discursos que las intentan convertir en víctimas pasivas, en traficantes de personas o en colaboradoras de la explotación sexual de menores, y que les reducen su capacidad de gestionar recursos públicos y privados. ${ }^{27}$

organización reciente vinculada a sectores conservadores; segundo, aquella de un reconocido grupo de organizaciones de mujeres y de derechos humanos colombianas; y, finalmente, la divulgada por la Red de Trabajadoras Sexuales de América Latina y el Caribe. Respectivamente: 1) $<$ http://cptratadepersonas.org/2012/04/26/denuncia-de-la-situacion-devulnerabilidad-de-las-victimas-de-trata-en-cartagena-colombia/>; $<$ http://www.humanas.org.co/amplia_not.php?id=f13e94c62ac403b02bad4967c870 4bbb> y 3) <http://www.redtrasex.org.ar/Abuso-de-poder-y-persecucion-a.html>. ${ }^{26}<$ http://www.nswp.org/resource/research-sex-work-12-sex-work-and-violence $>$. ${ }^{27}$ Ver también las páginas de la NSWP y de la RedTraSex: <http://www.nswp.org/ http://www.redtrasex.org.ar/>. 
Con especial énfasis, una edición del periódico Beijo da Rua, de la organización Davida - de Rio de Janeiro - y la Rede Brasileira de Prostitutas, está dedicado a combatir la violencia proveniente de estos discursos, alimentados hoy en Brasil con la excusa del Mundial de Fútbol de 2014 y de las Olimpiadas de 2016. ${ }^{28}$ Inclusive la organización Global Alliance Against Traffic in Women (GAATW), ha entendido que la manera como se han producido y divulgado las informaciones e ideas sobre "tráfico de mujeres" son más próximas al "rumor" que a cualquier tipo de dato confiable, y producen importantes perjuicios (GAATW, 2011).

Esta violencia, articulación de represión policial y discursividad jurídico-política, adquiere su sentido completo en la espectacularización mediática. Así se hizo evidente en el "caso Cartagena", y se hace en un reportaje del Canal Record (Brasil) del 25 de noviembre de 2011, en el que se muestra un operativo de la Policía Civil en un bar de Copacabana, Rio de Janeiro, para intentar detectar y capturar algunas mujeres que, según supuestas denuncias, tendrían en su poder medicamentos de venta restringida para drogar y asaltar clientes extranjeros. En este reportaje llama la atención la violencia ejercida por la presencia de las cámaras de televisión que invaden el espacio y la privacidad de todas las personas allí presentes. La violencia es ejercida por los periodistas (nuevamente integrantes del operativo policial): las mujeres huyen del arma en la que la cámara, con su poderosa luz blanca, se convierte. Ellas se tapan el rostro, piden que no las graben, corren, calculan el frame visual para poder huir de él. ${ }^{29}$

\footnotetext{
${ }^{28}<$ http://www.beijodarua.com.br/abril2012.pdf $>$.

${ }^{29}$ Agradezco a la socióloga austriaca Johanna Neuhauser por las informaciones y reflexiones. $\quad<$ http://videos.r7.com/garotas-de-programa-sao-detidas-por-aplicargolpes-em-copacabana-ri-/idmedia/4ed01356e4b0cce8566f4097.html>. Sobre las maneras como la Red Globo de televisión participa en la producción social de la prostitución, ver: Beleli e Olivar, 2011.
} 


\section{Consideraciones Finales... ¿Colombia y Brasil? ¿Violencia y prostitución? ${ }^{30}$}

Como el Estado, como "la policía", la prostitución no es una cosa que existe per se, extracultural y extracorpóreamente. La prostitución no es apenas un oficio o una práctica, es el nombre de un elástico, social y situacional conjunto de relaciones; una parcela de imaginación de raíces antiquísimas en la matriz occidental categorialmente femeninas y femenilizantes, que se actualiza de maneras diversas según territorios, tiempos $y$ relaciones corporales diferentes. Es una experiencia corporal de valor social altamente negativo (Pheterson, 1996; Rago, 1985; García, 2002; Juliano, 2006; Piscitelli, 2012). Es un referente a través del cual nos acostumbramos a imaginar la falta, la corrupción, lo maldito (como he oído repetidamente de prostitutas colombianas), lo "indigno" y por tanto el desprecio... y por tanto la compasión, la conmiseración. Un marco que parece favorecer, legitimar, disculpar acciones contundentes $e$ indiscutibles (destructivas $o$ misericordiosas) contra/sobre determinados seres humanos, determinadas prácticas, relaciones, redes y razones. En ese marco, prostituta, o puta, no es sólo aquella persona que cambia explícitamente sexo por dinero, es virtualmente cualquier mujer, cualquier persona que en una determinada relación performatice o corporifique algún rasgo o serie de rasgos determinados (Pheterson, 1996).

El espacio de resonancia de la inquietud prostitución/violencia es bastante amplio y complejo, implica la atención a escalas, relaciones y naturalezas distintas, y las intersecciones entre clase, género, edad, raza/color/etnia y procedencia, entre otras. Este artículo se ocupó apenas de un recorte, fuertemente asociado a la acción del Estado.

\footnotetext{
${ }^{30}$ Agradezco a las profesoras Maria Filomena Gregori y Mariza Correa, y especialmente a Adriana Piscitelli, por las sugerencias sobre una versión preliminar.
} 
En 2009 la Rede Brasileira de Prostitutas y la organización Davida, de Rio de Janeiro, que trabaja por los derechos de las prostitutas, publicaron algunos resultados parciales derivados de una investigación sobre "la cuestión prostitución y derechos" que estaban desarrollando en Brasil. En la lógica seguida por esa investigación militante, la vulneración de derechos implica violencia potencial o efectiva. Destaco que en 7 de las 11 ciudades mapeadas se denuncian diferentes formas de violencia policial, incluyendo agresión física, sexo forzado y el cobro de multas, "peajes" o "fianzas". ${ }^{31}$ En tres ciudades se destaca la acción violenta de grupos para-estatales, como "traficantes organizados", dueños de explotaciones mineras y gerentes de "zonas confinadas" (RBP/Davida, 2009).

Así, además del histórico agente "salud", otro agente estatal en particular se destaca por sus relaciones cotidianas, físicas, orgánicas, afectivas, sexuales, familiares, comerciales con la prostitución: la policía (o cualquier grupo armado de funciones análogas) (Rodrigues, 2003; Olivar 2010a). Entonces el protagonismo de grupos armados de control territorial, violencia sistemática y espectacular, y la gestión de zonas de tolerancia legales (Colombia), irregulares (Brasil) o simbólicas, nos ayudan en esa ida y vuelta a pensar las formas de la "transición política", de la democracia y sus modernidades comunicativas, cuando las vemos desde el dintel de un putiadero. La presencia de discursos religiosos en las experiencias de violencia y abuso de poder por parte del Estado en Porto Alegre, en Rio de Janeiro (Amar, 2009) o en Campinas $^{32}$, nos ayuda a pensar sobre todo un sistema de

\footnotetext{
${ }^{31}$ Vargas Ramírez, en su estudio sobre el barrio Santa Fe, en Bogotá, afirma que la violencia policial es también la que más afecta a las mujeres que ejercen la prostitución en esta "zona" (Vargas Ramirez, 2010).

${ }^{32}$ PostData: El 18 de outubro de 2013, estando este artículo al borde de la publicación, un policía militar, en día de descanso, fue asesinado en las inmediaciones del Jardim Itatinga, en Campinas (SP); una de las mayores zonas de prostitución de Brasil y de América Latina. Dos horas después comenzó una violenta retaliación de la Policía Militar contra los habitantes del barrio, que
} 
construcciones corporales/morales que atraviesa la guerra. Y la atención a la guerra en Colombia, nos ayuda a entender esta violencia brasileña como algo más que desajustes legislativos o comportamentales.

Siguiendo a Foucault diremos que la guerra funda las bases de la política (Foucault, 2008), y entre Brasil y Colombia, entre sectores más urbanos y más rurales, entre formas más "artesanales" y más "industriales" del mercado del sexo, evidenciamos guerras diferentes y políticas diferentes. En el Brasil urbano post-noventas primero triunfó la civilidad liberal - la "tolerancia", la botella descartable, la disimulación- y hoy parece vencer un conservatismo político de hálito evangélico (Amar, 2009) y palabras terroristas, altamente emotivo (Grupo DAVIDA, 2005; Beleli e Olivar, 2011; Olivar, 2011b; Piscitelli, 2012). Pero ese foco colombiano en la legitimación de la crueldad invierte el énfasis foucaultiano en la disciplina y el biopoder. Cuando miramos desde Colombia (Puerto Berrío como ejemplo) resalta la violencia latente, la intensificación del dolor, la culpa, el suplicio público de personas escogidas... algo que tiene que ver con las torturas a las prostitutas portoalegreneses de los años 80 , y que se distancia de la "gestión de la vida" que, aún en los discursos más conservadores, uno podría vislumbrar en el caso brasilero actual. Puro derecho a muerte.

Debajo de las formas más tradicionalmente políticas y de las razones económicas de la guerra y del control militar hay secreciones corporales que también son objeto de la guerra. Se dice que el desplazamiento forzado en Colombia no es un efecto colateral de la guerra sino una de sus razones primordiales. Lo mismo podemos decir sobre la colonización de la corporeidad.

incluyó un sitio de tres días, diversos crímenes y graves violaciones de derechos humanos. Este evento puede mudar las hipótesis aquí planteadas, pues actualiza un estilo de violencia extremamente brutal y performático en el gobierno de determinadas poblaciones y temas. Este evento es descrito y analizado por Aline Tavares en su tesis de maestría, PPGAS Unicamp/ PAGU, en fase de finalización. A ella le agradezco enormemente por la generosidad y las cuidadosas informaciones. 
Esta violencia sexual y de género en la guerra colombiana no es apenas un arma o una estrategia para la guerra, es la guerra en sí misma. Como en la democracia brasileña contemporánea puede ser su alianza creciente, a partir de 2000, con los discursos "antitráfico" e "anti-exploração". Es como si, siguiendo la lógica foucaultiana de fuerzas y flujos de poder, algunas prostituciones se produjeran como saberes sujetados, de los que se sospecha alguna fuerza atómica de contraefectuación de la sujeción. Ese es el mito del cuerpo de la puta, de la zona de tolerancia. Entonces no se golpea a la puta ni se produce su territorio suspendido apenas porque sea un cuerpo estructuralmente despreciable y yo pueda golpearlo, se sujeta porque tiene sentido en la producción de nuestras familias productivas, felices, eróticas, nucleares... porque la puta puede ser un jaguar (Olivar, 2011a). Y que el coyuntural golpe sea público y espectacular, con cámara de periodistas y discursos oportunistas, actualiza, en la capilarización del evento, toda una estrecha estructura ${ }^{33}$ que vincula género, sexualidad, clase, formas de trabajo, ocupación de la ciudad, conyugalidad, moda... La importancia de tener un futuro.

...o la violencia sistemática nos recuerda quiénes merecen vivir y cómo debemos hacerlo; produce humanos, vidas vivibles y relaciones deseables. Por la manera en que pensamos la prostitución, los de las putas parecen cuerpos cuya descartabilidad es anterior a la experiencia. No son vidas dignas de duelo, en palabras de Butler (2010). Su condición de "sin futuro" precede la enunciación del substantivo. Es decir, su suplicio está socialmente previsto y es necesario. He ahí la moraleja que se hace carne en los cuerpos de quienes vemos y de quienes viven: "The affect produced on the registres of the virtual and the potential, the fear that is real but not necessarily actualized in events, comes to constitute the ecology of fear in everyday life" (Das, 2007:9). Esa sea tal vez la condición de posibilidad de la prostitución en los contextos narrados. Esos son los Estados de los que estas

33 Uso "mito" y "sentido", estructura y coyuntura, en la lógica de Sahlins (1997). 
violencias nos hablan, los que se producen en la intensiva articulación de prostitución con violencia.

Finalmente, si el mito es para un lado lo es para todos. Si la puta es jaguar para ser cazado, también es cazadora fiera. Esa es otra guerra, otra quizá sin mayúscula, que se conecta con las grandes guerras y que no desprecia la violencia. Y esta es Dete, amiga y colega de Janete y de Solia, en Porto Alegre:

- Me golpearon mucho... Dentro de la Comisaría... En esa época, que era allá en la Jerónimo Coelho, creo... Me llevaron para dentro de la Comisaría, me cogieron en la Alfândega. ${ }^{34}$ Estaba con un pantalón blanco y una blusa roja. El oficial dijo: 'ah, esa alemana ahí está buena para llevárnosla allá para arriba'. 'Yo no voy para arriba ni qué mierda'. Entonces levantó la mano para golpearme en la cara. 'Pégame y vas a ver lo que hago contigo... Pégame, Pégame!!!! Que el único que me puede levantar la mano es mi papá... Pégame y te voy a agarrar...' Entonces él seguía con la mano levantada, no la bajaba, entonces me le fui pa encima... Bueno, yo sé que pateé tanto tanto a aquel hombre... y el agarrándome las manos, y yo con mis uñas bien pintadas de rojo, toda elegante, y él teniéndome las muñecas... y yo a patadas. Hasta que en un momento en que él no aguantó más y me soltó. 'Colega, saca esa mujer de aquí, manda esa mujer lejos de aquí!!' ‘¿¿¿Y no eras tú que me iba a pegar????? Pégame, entonces!!!' Entonces fui, firmé el "Atestado de Vadiagem" y me largué...

\section{Referencias bibliográficas}

AguSTín, Laura. Sex at the margins: migration, labour markets and the rescue industry. London/New York, Zed Books, 2007.

\footnotetext{
${ }^{34}$ La Praça da Alfândega es un espacio histórico muy importante del Centro de Porto Alegre y clásico punto de prostitución femenina (Fonseca, 2003; Gravina, 2006).
} 
Álvaro Rodriguez, Miriam. De las armas a la desmovilización: el poder paramilitar en Colombia. Revista Internacional de Sociología (RIS) vol.67, n 52, enero-abril, 2009, pp.59-82.

AMAR, Paul. Operation Princess in Rio de Janeiro: policing 'sex trafficking', strengthening worker citizenship, and the urban geopolitics of security in Brazil. Security Dialogue, vol. $40 \mathrm{n}^{\circ}$ s $4-5$ agosto/octubre 2009, pp.513-541.

AMNISTÍA INTERNACIONAL. Colombia: cuerpos marcados, crímenes silenciados. Violencia sexual contra las mujeres en el marco del conflicto armado. España, EDAI, 2004, p.2.

ARANGO, Luz Gabriela. Prostitución y derecho laboral. Centro latinoamericano en sexualidad y derechos humanos, 2010. $<$ http://www.clam.org.br/publique/cgi/cgilua.exe/sys/start.htm?UserA ctive Template $=\% 5$ FBR\&infoid $=7503 \&$ ok $=$ ok\&query $=$ simple \&sear ch\%5Fby\%5Fauthorname =all\&search \%5Fby $\% 5$ Ffield = tax\&search $\% 5$ Fby $\% 5$ Fheadline $=$ false\&search\%5Fby $\% 5$ Feywords =any\&searc $\mathrm{h} \% 5 \mathrm{Fby} \% 5$ Fpriority =all\&search $\% 5$ Fby $\% 5$ Fsection $=$ all\&search $\% 5 \mathrm{~F}$ by $\% 5$ Fstate $=$ all \&search $\% 5$ Ftext $\% 5$ Foptions $=$ all $\&$ sid $=21 \&$ text $=\mathrm{Lu}$ $z+$ Gabriela + Arango $>$.

ÁvilA, Samuel. Una plaza. Mujeres observadoras (y observadas) en un burdel del sur de Bogotá. En: Olivar, Justo, MORCILlO y SKAKCAUSKAS (org.). La prostitución hoy en América Latina: entre trabajo, políticas y placer. Campinas, SP, Núcleo de Estudos de Gênero - PAGU/Unicamp, en edición (2013).

BANNACHIE \& MARIE. Their words are killing us. Research for Sex Work (12), 2010, pp.24-25.

BARRAZA y CAICEDO. Mujeres entre mafiosos y señores de la guerra. Bogotá, Corporación Humanas, 2007.

BELELI, Iara e OLIVAR, JM. Prostituição e mobilidade na mídia brasileira. En: PISCITELLI, ASSIS e OlivAR (org). Gênero, sexo, amor e dinheiro: mobilidades transnacionais envolvendo o Brasil. Campinas, SP, Núcleo de Estudos de Gênero-Pagu/Unicamp, 2011.

BUTLER, Judith. Marcos de guerra: las vidas lloradas. Barcelona, Paidós, 2010. 
...bajo el dintel del putiadero

CEDAW. Concluding observations of the Committee on the Elimination of Discrimination against Women: Brazil. United Nations, 2012.

Coletivo HetiaRA. Some uncomfortable questions - Government policies in Spain and impact on people who sell sex voluntarily. Research for Sex Work (12), 2010, pp.17-18.

Colombia. Código Penal, Ley 599 de 2000. En: www.jurimprudencias.com

CORPORACIÓN HumANAS - Centro Regional de Derechos Humanos y Justicia de Género. Guía para llevar casos de violencia sexual. Propuestas de argumentación para enjuiciar crímenes de violencia sexual cometidos en el marco del conflicto armado colombiano. Bogotá, Humanas, 2009.

CORPORACIÓN HUMANAS. Informe de derechos humanos de las mujeres y justicia de género. Colombia 2009-2010. Bogotá, Corporación Humanas, 2011.

Corte Constitucional De Colombia. Sentencia T629 de 2010.

Corte Constitucional De Colombia. Sentencia T620 de 1995.

DAS, Veena. Violence, gender and subjectivity. Annu. Rev. Anthropol. 37, 2008, pp.283-99.

. Life and words: violence and the descent into the ordinary. Berkeley, University of California Press, 2007.

DELEUZE, Gilles. Foucault. São Paulo, Brasiliense, 1991.

FONSECA, Claudia. Familia y profesión: la doble carrera de la mujer prostituta. La antropología brasileña contemporánea: contribuciones para un diálogo latinoamericano. Buenos Aires, Prometeo, 2003, pp.95-135.

Foucault, Michel. Em defesa da Sociedade. São Paulo, Martins Fontes, 2008.

GAATW. What's the cost of a rumor? A guide to sorting out the myths and the facts about sporting events and trafficking. Bangkok, Global Alliance Against Traffic in Women, 2011. 
GARCíA, Carlos Ivan. La prostitución en la segunda mitad del siglo XX: dinámica de la mo(ral)dernización. MARTínEZ, A. y RODRíGUEZ, P (org.). Placer, dinero y pecado: historia de la prostitución en Colombia. Bogotá, Aguilar, 2002, pp.281-325.

GRAVINA, Heloisa. Ser da praça: performance-etnografia na Praça da Alfândega, Porto Alegre. Dissertação de Mestrado em Antropologia Social, UFRGS, Porto Alegre, 2006.

GRUPO DAVIDA. Prostitutas, 'traficadas' e pânicos morais: uma análise da produção de fatos em pesquisas sobre o 'tráfico de seres humanos'. Cadernos Pagu (25), Campinas, SP, Núcleo de Estudos de Gênero-PAGU/Unicamp, 2005, pp.153-185.

JULIANO, Dolores. Excluidas y Marginales. Madrid, Ediciones Cátedra, 2006.

KEMPADOO, Kamala; SANGHERA y PATTANAIK (comp). Trafficking and prostitution reconsidered: new perspectives on migration, sex work and human rights. Boulder, Paradigm Publishers, 1995.

MUJER Y CONFLICTO ARMADO, Mesa de trabajo. Informe sobre violencia sociopolítica contra mujeres, jóvenes y niñas en Colombia. Tercer informe. Bogotá, 2002.

OlivaR, José Miguel. Banquete de homens: sexualidade, parentesco e predação na prática da prostituição feminina. Revista Brasileira de Ciências Sociais, vol. 26, n 75, fevereiro, 2011a, pp.89-189.

Apresentação: E... você, conhece alguém que trafique pessoas? Fórum Tráfico de pessoas, novas flexões no debate, organizado em colaboração com Marcia Anita Sprandel. 35 Encontro Anual da ANPOCS, 27 de outubro de 2011b.

- Guerras, trânsitos e apropriações: políticas da prostituição de rua a partir das experiências de quatro mulheres militantes em Porto Alegre, Brasil. Tese de Doutorado em Antropologia Social, Universidade Federal do Rio Grande do Sul, Porto Alegre, 2010a.

. Trabalho sexual: entre direitos trabalhistas e condenações morais... ou o liberalismo em conserva. Comentário sobre a sentença T-629 de 2010 da Corte Constitucional de Colômbia. Sexuality Policy Watch, $2010 b$. $<$ http://www.sxpolitics.org/pt/wp- 
...bajo el dintel del putiadero

content/uploads/2009/02/olivar-ts-entre-direitos-laborais-e-condenasmorais-07112_port.pdf $>$.

. A angústia dos corpos indóceis: prostituição e conflito armado na Colômbia contemporânea. Cadernos Pagu (31), Campinas,SP, Núcleo de Estudos de Gênero-Pagu/Unicamp, julhodezembro de 2008, pp.365-397.

Olivar, José Miguel y PACHECO, Carlos. Which conflict? Which body? Which nation? prostitution, gender and violence in the Colombian 'post conflict' context. In: GermaIN, Tonia St.; DEWEY, Susan. (Org.). Conflict-Related Sexual Violence: international law, local responses. Sterling, VA, Kumarian Press, 2012.

OXFAM. Saquen mi cuerpo de la guerra: violencia sexual en contra de las mujeres en el contexto del conflicto armado colombiano 2001-2009. Oxfam, 2010.

PHETERSON, Gail. The prostitution prism. Amsterdam, Amsterdam University Press, 1996.

PISCITELl, Adriana. Cuidado, limpeza e carinho, domesticidade, trabalho e vínculos amorosos entre migrantes brasileiros que oferecem serviços sexuais. Seminário Domesticidade, modos de usar. Rio de Janeiro, Museu Nacional, 3 de maio de 2012.

- Amor, apego e interesse: trocas sexuais, econômicas e afetivas em cenários transnacionais. En: PISCITELLI, ASSIS e OLIVAR (org). Gênero, sexo, amor e dinheiro: mobilidades transnacionais envolvendo o Brasil. Campinas, SP, Núcleo de Estudos de GêneroPagu/Unicamp, 2011a, pp.537-582.

- Procurando vítimas do tráfico de pessoas: brasileiras na indústria do sexo na Espanha. Revista interdisciplinar da mobilidade humana, vol. $19 \mathrm{n}^{\circ} 37,2011 \mathrm{~b}$.

- Apresentação: novos desafios no debate sobre tráfico de pessoas no Brasil. Fórum Tráfico de pessoas, novas flexões no debate, organizado em colaboração com Marcia Anita Sprandel e José Miguel Nieto Olivar. 35 Encontro Anual da ANPOCS, 27 de outubro de 2011c. 
. Entre as 'máfias' e a 'ajuda': a construção de conhecimento sobre tráfico de pessoas. Cadernos Pagu (31), Campinas, SP, Núcleo de Estudos de Gênero-Pagu/Unicamp, julho-dezembro de 2008, pp.29-64.

PRADA, Nancy et al. iA mí me sacaron volada de allá! Relatos de vida mujeres trans desplazadas forzosamente hacia Bogotá. Bogotá, Universidad Nacional de Colombia y Alcaldía Mayor de Bogotá, 2012.

RAGO, Margareth. Do cabaré ao lar: a utopia da cidade disciplinar, Brasil 1890-1930. Rio de Janeiro, Paz e terra, 1985.

RBP/DAvidA. Direitos Humanos e Prostituição Feminina. Rio de Janeiro, RBP/Davida, 2009.

RESTREPO, Laura. La Novia Oscura. Bogotá, Alfaguara, 2007.

REVISTA SEMANA. "EUA reconoce a Colombia como uno de los países con mayor explotación sexual", Bogotá 24 de abril de 2012.

RODRIGUEZ, Marlene. Polícia e prostituição feminina em Brasília - Um caso de estudo. Tese de Doutorado em Sociologia, UnB, Brasília, 2003.

SAHLINS, Marshall. Ilhas da história. Rio de Janeiro, Jorge Zahar, 1997.

TEDESCO, Letícia. Explorando o negócio do sexo: uma etnografia sobre as relações afetivas e comerciais entre prostitutas e agenciadores em Porto Alegre. Dissertação de Mestrado em Antropologia Social, UFRGS, Porto Alegre, RS, 2008.

VARGAS, Ramirez; HILDA, Patricia. Exclusión social de mujeres que han ejercido la prostitución en Colombia. Master GEMMA. Universidad de Granada/Universidad de LODZ, Polonia, 2010. 